\title{
The Aesthetics Analysis of Three Dimensional Animation Modeling
}

\author{
Peng Li \\ School of Animation and Digital Arts \\ Communication University of China \\ Beijing, China
}

\begin{abstract}
This paper first defines the scope of three dimensional animation concept, analyzes the two aesthetic orientations of three dimensional animation modeling, and illustrates the aesthetic features obtained by three dimensional animation itself, thus make analysis on the aesthetic process of three dimensional animation modeling in terms of aesthetics.
\end{abstract}

Keywords - three dimensional animation; skeuomorphism; object and surface; aesthetic relation; subject and object

\section{INTRODUCTION}

The three dimensional animation is the animation with three dimensional depth made by the binary digit that called by computer program in the virtual environment and presented on the basis of surface. Compared with hand painted animation, the production of three dimensional animation relies on the calling and running of computer program, rather than simply painting expression. The production of three dimensional animation is mostly completed in the computer generated virtual environment by the creator, which foundation of realization is binary digit. It uses digit to present the position of point, defines line by the position of points, fixes surface by lines, and forms dimension by surfaces. The binary digits in computer realize visual moving effects by the calling and calculating of various programs in the software. However, the two dimensional animation paints the detail sketch of the objects by hand painting, and restores the moving effects of the objects by playing the detail sketch. The base of three dimensional animation modeling aesthetics is the aesthetics of digits, but two dimensional animation belongs to the aesthetics of line which featured by hand painted lines. The presentation mode of hand painted animation regards line as the core, which is beneficial to convey emotional messages, while the three dimensional animation uses surface to present object, which is beneficial to convey the volume and space depth messages.

\section{THE DEVELOPMENT OF THREE DIMENSIONAL} ANIMATION MODELING DisPlays Two AESTHETIC

ORIENTATIONS, WHICH ARE THE PURSUIT OF GENERALIZATION AND THE PURSUIT OF SKEUOMORPHISM

These two kinds of modeling have their own advantages in their aesthetic pursuit. The pursuit of generalization is best presented in the American animation, while the pursuit of skeuomorphism is best presented in Japanese animation. In American animation, the modeling is mainly composed by generalized object and surface. The generalized geometries almost compose all objects, including most natural objects in the environment. This kind of aesthetics does not need to stimulate the real objects in the real world, so it is not bound by the corresponding objects in the real world. The highly generalization of modeling makes the cartoon characters possess the maximum range of movement limitation, and the cartoon character can make more exaggerated movements. Therefore, a high degree of flexibility is the greatest advantage of this kind of aesthetic pursuit. The orientation of pursuing generalized modeling in the three dimensional animation makes the audience agrees with the reasonability of the character created by the creator in the first time seeing the character. This kind of acceptance is like a kind of agreement, making the audience not too picky on whether it is lifelike. Under this precondition, the creator has high flexibility in aspects like the performance of the characters, story rhythm, the range of motion and so on. This highly free flexibility greatly adds the expressive force of the work. However, generalized modeling is inappropriate to present serious theme, especially themes with strong reality sense. It is because that the generalized modeling itself has a kind of alienation effect, easy to produce distance from the audience's daily life, and this distance makes the audience agrees with the assumption of the work. When presenting serious and real themes, this kind of aesthetic pursuit with a high degree of generalization becomes the negative factor instead. Especially in the animation that presents reality sense, if it is expressed by generalized modeling, the form and content would be highly inharmonious.

Another aesthetic orientation of three dimensional animation is skeuomorphism realism. The real world is the material world, in which line does not exist. Object and surface constitute the basic form of material in the real world. The skeuomorphism realism stimulates the real world in the form of object and surface, which adds the possibility of the infinite realism inclination of the three dimensional skeuomorphism. The reason why simulation is not used here is that simulation cannot present the virtuality of computer. This kind of virtuality emphasizes the phantom constructed without base but is the same with the real object in the computer environment. This virtual simulation has essential difference with the simulation taking certain material as the 
object in the real world, because the former virtuality takes digital environment as the base, while the latter takes certain material as the base. The skeuomorphism animation pursuits highly consistence of the objective image in the work and in reality. This aesthetics ideal is similar with the ideal of copying the real world in photography, which aim is build highly consistent virtual objective image with the real world. Verisimilitude is the basic standard of this kind of aesthetic pursuit, which can be found in Japanese three dimensional animation. For example, in "Final Fantasy: Advent Children", the modeling image is created based on the precondition of highly virtual reality. The skeuomorphism aesthetics pursuit adding with strong digital integration capability of the computer makes the creator create images that does not exist in the world freely. The creator can integrate this kind of image with the real image, creating a world that cannot be distinguished between reality and illusion. In this aspect, the typical example is "Avatar". In this movie, the verisimilitude of characters and sceneries is breathtaking, which is the result of taking skeuomorphism as the precondition and using computer digital processing. The pursuit of skeuomorphism aesthetic style bedims the boundary of reality and virtuality. It integrates the real and virtual to achieve visually lifelike image. This kind of aesthetic pursuit expands the creator's range of subjects, making the creator not be confined to material in the real world, but employs the sense material in imagination actively. There is no boundary in human imagination, so there is no boundary for the creator to create non-exist object using computer. The creator is befitted by the skeuomorphism aesthetic pursuit of three dimensional animation, making it possible to create animation in the infinite range of real and imaginary materials. In addition, the combination of the skeuomorphism aesthetic pursuit of three dimensional animation and the virtual reality technology can make great contribution to the construction of "virtual world". Of course, the skeuomorphism aesthetic pursuit of three dimensional animation has is limitation. In the performance of animation characters, the skeuomorphism feature affects its flexibility instead. The skeuomorphism itself takes real world as the basic model, which is the simulation of the real world. It requires not only the replication of the real objective image, but also the different force fields existed in the real world, such as gravity, friction force and so on. Physical factors in the real world restrain the objects' range of motion, so the skeuomorphism aesthetic pursuit has its limitation. This limitation is not displayed on material, but on the movement of material, because the material moving style under this kind of aesthetic pursuit must seemingly conform to the law of different force fields in the real world. If the imaginative object is similar with the object in the real world in form, but its movement does not conform to the law of different force fields in the real world, the expression would create a sense of false to the audience, which is against the skeuomorphism aesthetic pursuit. Therefore, the three dimensional animation with skeuomorphism aesthetic pursuit tends to be the realistic subject with strong sense of reality. The serious, rational and realistic theme is more appropriate to be presented by skeuomorphism modeling. Similarly, the humorous, emotional and lively theme is more appropriate to be presented by generalization modeling.

\section{THE AESTHETIC FEATURES OF THREE DIMENSIONAL ANIMATION ARE OBJECT AND SURFACE, SPECTACULARITY, VIRTUALITY AND DUCTILITY}

The object and surface in three dimensional animation aesthetics are mainly reflected in the basic presentation form of object and surface in three dimensional animation, using surface to constitute object and forming the space depth by object. This feature of "object and surface" is different with the "liner" feature in hand painted animation that uses line as the major manner to convey emotion. It is less expressive than the expression of "line" in conveying emotion, but is superior to "liner" feature in expressing the depth of space. It is because that there is no "line" in the real material world. It is the "object and surface" that constitute the basic form of objects in the real world. This "object and surface" feature make three dimensional animation has the advantages in presenting volume of object and the space depth. The spectacularity of three dimensional animation has some relation with virtuality. We can also say that it is the virtuality that makes the spectacularity of three dimensional animation be possible. The presentation of three dimensional animation takes digits that don't exist in the real world as the base. The creator use software program to transfer the digits in computer into visual images. Because digit itself is abstract and non-material, therefore the beginning of three dimensional animation images is virtual, starting with the digits in virtual environment. The process of producing three dimensional animation is also virtual because the whole process is completed in virtual computer environment. The final presentation of three dimensional animation image is non-material image that does not exist, which is also virtual. Therefore, the three dimensional animation image itself has the virtual feature. Combine with its aesthetic pursuit, this virtual feature produces the feature of virtuality. The "simulation" in virtuality is the description of purpose, which is the simulation of the material world. The virtuality here is different with the skeuomorphism mentioned before, which is only one presentation of the virtuality. Virtuality itself also includes the object and movement that simulate the material world by generalization. The production of hand painted animation relies too much on material condition, and thus is not virtual enough. When simulating the material world, line is to suppositive that cannot be enough close to the real material world. Because the hand painted animation is not virtual enough and similar enough, it does not have the vurtuality feature of three dimensional animation. The feature of "object and surface" of three dimensional animation tends to be the same with the "non-liner" of object in the material world. Therefore, the three dimensional animation can virtualizes the real world and be infinitely close to the real world. The virtuality of three dimensional animation results to the feature of spectacularity, which is presented in that three dimensional animation can create spectacle that does not exist in the world with its capability of infinitely close to images in the real world. Although this spectacle is created, it has the sense of reality infinitely close to the real world, which cannot be realized by the hand 
painted animation. The ductility of three dimensional animation lies in that three dimensional animation can present objective image not only in the generalized manner, but also in the manner that infinitely close the real world. These two orientation make three dimensional animation itself has unprecedented ductility, exaggerated or close to reality without limits in subject, character modeling, performance, representation of style and so on. This infinite ductility provides the creator with infinite freedom in creation, which is incomparable than any other kind of animation. In the way of pursuing aesthetics, the three dimensional animation realizes the objective of "nothing is unreachable if you think hard".

\section{The Aesthetic Relation Analysis of the ThreE DIMENSIONAL ANIMATION MODELING}

The aesthetic reception process of three dimensional animation modeling is also closely related to three parts, namely modeling, the creator and the audience. It is not the static activity that takes one part as the center. The aesthetic reception of three dimensional animation modeling is a dynamic activity, as well as the activity with constant communication, mutual transformation and integrates the subject and object into one. The objective image itself carries the ideal of the creator, and thus has the possibility of moving the audience and communicating with the audience. The perceptivity obtained by the audience is the precondition of communication. The image produced by three dimensional animation modeling arouses the perceptivity of the audience. With the effect of empathy, the image and the audience have constant communication, and the mutual communication and transformation between the subject and object integrates them into one. It is this process that makes the audience feel the beauty of the three dimensional animation images. This kind of aesthetics activity is the interaction between the subject and object, which cannot be described by the tendency of simply fixed subject or object. The specific process of this activity should be: the creator and the audience are under the same environment composed by different factors like politics, economy, culture, history, region, race and so on, which is the precondition of the communication between the creator and the audience. The audience can interpret the meaning of the work and understand the beauty of the work's modeling according to the macro environment. However, no matter the creator or the audience, they would be affected by their personal factors like personality, temperament, age, hobby, career, class and so on. Their communication has some asymmetry in certain degree, that is to say there is possibility that the meaning included in the creator's work cannot be understood. The audiences rarely understand the original meaning of the creator in the work if illustrate the work according to their personality. The creator's work first exists in his mind in the form of creative ideas, and then be presented in the work by three dimensional technology. The modeling image created this way is affected by the internal and external environment of the creator, which is the production of the combination of the creator's ideas and the environment. The audience interprets the work through his personality combining with the historical background. This kind of interpretation is the restoration of the work's modeling meaning in a certain degree. However, because personality factors exist in this process, the audience tends to produce personal interpretation, which cannot restore the original meaning of the creator. The same macro environment of the three dimensional animation creator and the audience is the key in the interpretation of the work, which is the overlapping area obtained by both parts. The three dimensional animation is not the traditional artistic work. Its target is the public, pursuing in time and effective communication with the public. If this kind of effective communication cannot be realized, it means the failure of the work. The three dimensional animation can be divided into artistic and business. In business three dimensional animation, the failure of the work means the possibility of the box office decline. The appreciation of artistic animation belongs to non-utility aesthetics, how about business animation? The appreciation object of business animation is story and expression form. In the process of identifying whether it's beauty or not, business and artistic animation all do not involve with gains and losses. In the process of feeling story and expression form, the audiences also do not has utility purpose. Therefore, the appreciation of business animation also belongs to aesthetic activity. The purposes of viewing and utility are different and cannot be mixed. Whether it is beautiful or not in three dimensional animation modeling is related to the interpretation of the audience, as well as to the creation of the creator. The business three dimensional animation produced by the creator faces with the danger of failure if it is not accepted by the audiences, which increases the possibility of failure of the box office. In order to make sure that the work's modeling beauty is in consistence with the needs of audiences, the creator should make survey on the audiences in advance, and produce three dimensional images that meet the expectation of the audiences. The audience also reflects the problems existed in the images through various ways after watching. This active communication ensures the reception of the modeling in the largest degree, and also ensures the mastery of the audience's needs for the creator. Simply from the aesthetic process of the audience, the audience takes materials as the base (material is composed by the screen and the images), and the materials touch the audience. The audience interprets the material after feeling the touch, and tries to restore the original meaning conveyed by the creator in the interpretation. At the same time, empathy is also produced in this process. Therefore, the materials become me and me the materials, the process of integrating materials and me into one constitutes the subject and object activity in the audience's aesthetics. This is the three dimensional animation image aesthetic activities. 


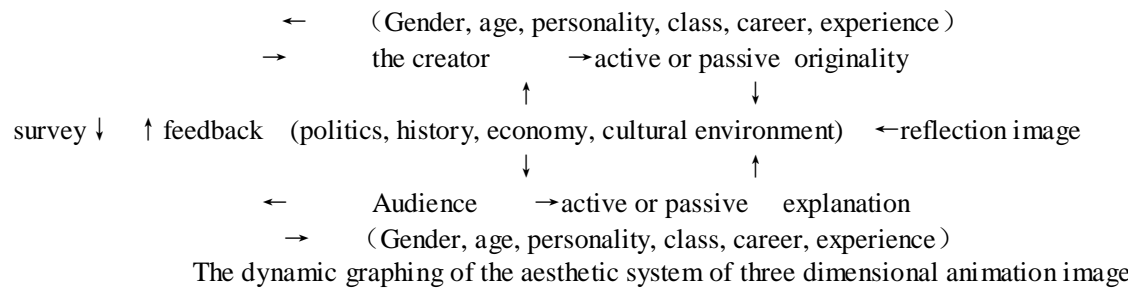

To sum up, the concept of three dimensional animation is appropriate to describe the amination with space depth and takes "object and surface beauty" as the basic presentation produced by computer. Both the two orientations of three dimensional animation can present the aesthetic feature obtained by the three dimensional animation itself. These aesthetic features are included in the three dimensional animation modeling that constitutes the precondition of aesthetics. In the audience's aesthetics, the communication between audience and the creator add the possibility of the success of the work. The audience's aesthetics towards three dimensional animation modeling is a systematic dynamic activity, is a changing condition that transfer between subject and object and integrate together into one.

\section{REFERENCES}

[1] Zhu Guangqian. History of the Western Aesthetics [M]. Beijing: People's Literature Publishing House, 1979.5

[2] Ye Lang. The Outline of Chinese Aesthetic History [M]. Shanghai: Shanghai People's Publishing House, 1985.11

[3] Li Zehou. Three Books of Aesthetics [M]. Tianjin: Tianjin Academy of Social Science Publishing House, 2003.10 